\title{
CINEMA
}

\section{CINEMAS AFRICANOS E OS MEANDROS DA VISIBILIDADE}

\author{
AFRICAN CINEMAS AND THE MEANDERS OF VISIBILITY \\ CINES AFRICANOS Y LOS MEANDROS DE LA VISIBILIDAD \\ José Francisco Serafim \\ Ana Camila Esteves ${ }^{2}$ \\ Morgana Gama de Lima³
}

RESUMO: esse artigo discute questões relacionadas à construção de discursos analíticos sobre filmes africanos e como os critérios utilizados no processo de difusão e consagração dessa cinematografia reservam uma estreita relação com duas instâncias mediadoras: festivais/mostras e a academia. Argumentamos que a adoção de diferentes abordagens críticas parte de um processo de retroalimentação entre essas duas instâncias que, ao funcionarem como espaços de comunicação, orientam o conteúdo dos textos crítico-analíticos que circulam nestes espaços e, como consequência, restringem a percepção dessa cinematografia a determinados paradigmas. Considerando a importância dos festivais/mostras e da academia para a legitimação dos cinemas africanos e seus papéis como mediadores, fazemos uma breve análise de catálogos produzidos em três mostras sobre filmes africanos no Brasil entre 2015 e 2017, a fim de compreender as lógicas discursivas que orientam a produção de textos críticos sobre a cinematografia africana, e suas consequências sobre a visibilidade destes filmes.

Palavras-chave: Cinemas africanos. Mediação. Academia.

ABSTRACT: this article discusses issues related to the construction of analytical discourses on African films and how the criteria used in the process of diffusion and acclaim of

\footnotetext{
ORCID: 0000-0003-3736-6818. E-mail: serafimjf@gmail.com

2 ORCID: 0000-0001-6175-0284. E-mail: anacamila.ufba@gmail.com

ORCID: 0000-0002-7589-8332. E-mail:morganagama@gmail.com
} 
this cinematography have a close relation with two mediating instances: the festivals and the academy. We argue that the adoption of different critical approaches starts from a process of feedback between these two instances that, by working as spaces of communication, guide the content of the critical-analytical texts that circulate in these spaces and, therefore, restrict the perception of this cinematography to specific paradigms. Considering the importance of the festivals and the academy for the legitimacy of African cinemas, and their roles as mediators, we make a brief analysis of catalogs produced in three festival programs about African films in Brazil between 2015 and 2017, in order to understand the discursive logics that guide the production of critical texts on African cinematography, and its consequences on the visibility of these films.

Keywords: African cinemas. Mediation. Academy.

RESUMEN: este artículo discute cuestiones relacionadas con la construcción de discursos analíticos sobre películas africanas y cómo los criterios utilizados en el proceso de difusión y consagración de esa cinematografía reservan una estrecha relación con dos instancias mediadoras: festivales / muestras y la academia. Argumentamos que la adopción de diferentes enfoques críticos parte de un proceso de retroalimentación entre esas dos instancias que, al funcionar como espacios de comunicación, orientan el contenido de los textos crítico-analíticos que circulan en estos espacios y, como consecuencia, restringen la percepción de esa cinematografía a ciertos paradigmas. Considerando la importancia de los festivales / muestras y de la academia para la legitimación de los cines africanos y sus papeles como mediadores, hacemos un breve análisis de catálogos producidos en tres muestras sobre películas africanas en Brasil entre el 2015 y el 2017, a fin de comprender las lógicas discursivas que orientan la producción de textos críticos sobre la cinematografía africana, y sus consecuencias sobre la visibilidad de estas películas.

Palabras clave: Cines africanos. La mediación. Academía.

\section{Introdução}

Por que razão a maior parte dos pesquisadores dos cinemas africanos prefere analisar a produção fílmica do continente a partir de uma perspectiva autoral, pautada na trajetória do cineasta, ou de uma abordagem voltada para a discussão de representações, do pós-colonialismo e da dicotomia entre tradição e modernidade no contexto da cultura africana? O que motiva essas escolhas além da própria narrativa fílmica? Como bem assinalou Mahomed Bamba, pesquisador dos cinemas africanos no Brasil, "todo filme é portador de seus próprios opera- 
dores de leitura/interpretação, enquanto outra parte do processo de interpretação depende de diversos fatores e determinações contextuais e institucionais" (BAMBA, 2013, p. 235). Este artigo, portanto, parte da necessidade de pensar os mecanismos institucionais que precedem, mediam e condicionam os discursos construídos sobre filmes da África, resultantes de escolhas específicas que interferem no processo de interpretação dos filmes e que, por sua vez, orientam os processos de visibilidade e consagração desta cinematografia.

Essa preocupação também parte da leitura de um percurso já traçado por Mahomed Bamba no artigo "Os espaços de recepção transnacional dos filmes: propostas para uma abordagem semiopragmática" (2013). Como ponto de partida de sua reflexão acerca da recepção transnacional de filmes africanos, Bamba entende o contexto de estudos do World Cinema como um campo constituído por microespaços de comunicação, recepção e leitura fílmica. Dentro deste microespaço se configuram o que o autor chama de "modos de leitura acadêmica do cinema africano" (2013, p. 225), que se "materializam" ou são operacionalizados através de espaços de eventos onde ocorre a recepção transcultural (festivais de cinema) e através de modos de leitura analítica e teórica dos filmes no campo acadêmico (revistas científicas e catálogos ${ }^{4}$ ).

Enquanto o pesquisador buscava investigar a construção desses "espaços de comunicação"5 a partir de uma perspectiva semiopragmática ${ }^{6}$ para compreender a interação entre filme e espectador no processo de recepção transnacional, nos é primordial aqui pensar esses espaços de comunicação (festivais e academia) enquanto instâncias institucionalizadas, com uma lógica discursiva própria no campo do cinema, que funcionam como importantes mediadores no processo de produção de discursos e, por sua vez, orientam a interpretação de filmes africanos no contexto de estudos teóricos em cinema. Acreditamos que compreender as lógicas internas desses dois espaços pode ser profícuo no intuito

\footnotetext{
4 Os catálogos produzidos em mostras e festivais, de modo geral, funcionam como um guia da programação, no entanto, no Brasil e em outros países, tem se tornado comum aproveitar esse tipo de publicação para apresentação de textos crítico-analíticos sobre os filmes exibidos escritos por pesquisadores e críticos de cinema. Como pretendemos demonstrar ao longo deste artigo, não só os textos dos catálogos de mostras de cinemas africanos, como a própria curadoria destes eventos, são assinados por pesquisadores, justificando nossa escolha em categorizar o catálogo como publicação que acolhe textos de natureza acadêmica.

5 Esse conceito utilizado por Mahomed Bamba é apresentado por Roger Odin no seu livro Les espaces de communication (2011) em referência à mediação operacionalizada pelas instituições sociais, inclusive, as informais como a família.

6 O autor justifica a escolha por essa abordagem nos seguintes termos: "Optamos por uma abordagem semiopragmática na medida em que nosso interesse está, primeiramente, na construção teórica dos 'espaços de comunicação' em que se configuram os modos de leitura acadêmica dos filmes africanos” (BAMBA, 2013, p. 225).
} 
de investigar a lógica que orienta a produção de sentido sobre a cinematografia africana e suas possíveis implicações.

Em entrevista à Julien Péquignot, Roger Odin (2017) esclarece que aqueles que reivindicam o termo semiopragmática concordam com a ideia de que o contexto deve ser o ponto de partida para a produção de significado, sobretudo no que se refere à influência de instituições no processo de produção de sentido. Como parte dessa mesma entrevista o autor esclarece o porquê de adotar o termo "espaços de comunicação" para lidar com o contexto:

\begin{abstract}
Tomar como eixo de relevância a noção de instituição é uma maneira de limitar o contexto, mas percebi que havia muitos contextos nos quais fazíamos e víamos os filmes que não eram instituições. Eu então, mudei para a noção de espaço de comunicação, que era mais amplo, mais flexível. No interior dos espaços de comunicação, existem instituições patenteadas e outros tipos de estruturas menos institucionais. Um grupo de jovens, por exemplo, não é uma instituição e, portanto, é um espaço de comunicação especial (ODIN; PÉQUIGNOT, 2017, p. 120, grifo nosso, tradução nossa) ${ }^{7}$.
\end{abstract}

Argumentamos, portanto, que os filmes produzidos por cineastas africanos, à semelhança de outras produções cinematográficas emergentes no cinema mundial, devem a sua legitimação em boa medida a esses filtros institucionais ${ }^{8}$. Em artigo no qual analisa como a obra do cineasta mauritano Med Hondo aparece na produção acadêmica no campo dos estudos sobre os cinemas africanos, a pesquisadora espanhola Beatriz Leal Riesco (2014) argumenta que a instância acadêmica exerce ainda muita influência sobre a valoração da cinematografia africana. O papel dos curadores e programadores dos festivais de filmes africanos no mundo muitas vezes é assumido por pesquisadores do campo, o que significa que as mesmas pessoas que determinam que filmes devem ser exibidos são também as que decidem sobre quais deles são relevantes para a pesquisa acadêmica. Riesco acrescenta que o público desta cinematografia acaba por se

\footnotetext{
7 Do original: Prendre comme axe de pertinence la notion d'institution, c'est une façon de limiter le contexte, mais je me suis aperçu qu'il y avait beaucoup de contextes dans lesquels on faisait et on voyait des films qui n'étaient pas des institutions. Je suis donc passé à la notion d'espace de communication, qui était plus large, plus souple. À l'intérieur des espaces de communication, il y a des institutions patentées et d'autres types de structures qui sont moins institutionnelles. Un groupe de jeunes, par exemple, ce n'est pas une institution et, pourtant, c'est bien un espace de communication particulier.

8 Ainda que seja importante mencionar que a crítica jornalística e a recepção via plataformas web como Netflix e YouTube hoje se configuram em espaços de comunicação com muita força sobre os hábitos espectatoriais tanto na África quanto fora dela.
} 
tornar restrito a esses espaços de comunicação, de modo que entre eles existe uma espécie de dependência e retroalimentação:

Devido à precária difusão comercial destes filmes, suas projeções se circunscrevem em grande medida a aulas universitárias e a festivais de cinema. Sua audiência é, portanto, educada e instruída, caracterizada por se aproximar da obra seja através da leitura crítica, seja através de um mediador informado: um professor universitário ou especialista em festival, dois papéis que, em muitos casos, se atravessam. Neste contexto de distribuição, exibição e recepção mediada, as opiniões da crítica se convertem em camisas de força, limitando o alcance do acesso aos filmes (RIESCO, 2014, p. 165-166, tradução nossa) ${ }^{9}$.

A escolha por abordar o filme a partir de uma perspectiva específica (histórica, política, nacionalista, culturalista etc.) dialoga com determinadas tradições e filiações teóricas com implicações diretas sobre a circulação do filme nos espaços de comunicação (seja sua exibição em festivais e mostras como sua análise em produções acadêmicas) - e também na própria lógica de produção, uma vez que uma recepção favorável por essas instituições pode, por exemplo, resultar na obtenção de premiações, incentivos financeiros, além do aumento da possibilidade de distribuição internacional. Entendemos, portanto, que para uma apreciação crítica de filmes africanos não basta a escolha por uma vertente teórica ou outra, mas a forma como o pesquisador as coloca em disputa e, consequentemente, produz discursos e significados sobre as obras. Logo, o nosso desafio aqui é pensar quais fatores ou agentes interferem na construção de discursos sobre os cinemas africanos apresentados especificamente em catálogos de algumas mostras desta cinematografia no Brasil, entre os anos de 2015 e 2017. A princípio, para entender a escolha por uma determinada abordagem, é preciso atentar para a conjuntura dos estudos da cinematografia africana com o fim de entender as possíveis motivações ou fatores que orientam a preferência por uma abordagem ou outra.

Como parte dos fatores que interferem nessas escolhas está a própria denominação "cinema africano". Ao tempo em que a utilização do termo "africano" põe em relevo a proveniência geográfica desses filmes, uma forma de mostrar a autonomia

\footnotetext{
9 Do original: Debido a la precaria difusión comercial de estos filmes, sus proyecciones se circunscriben en gran medida a aulas universitarias y a festivales de cine. Su audiencia es, por tanto, educada e instruida, caracterizada por acercarse a la obra bien después de la lectura crítica, bien a través de un mediador informado: un profesor universitario o especialista en un festival, dos roles que, en muchos casos, se solapan. En este contexto de distribución, exhibición y recepción mediado, las opiniones de la crítica se convierten en camisas de fuerza, limitando el alcance del acceso a las películas.
} 
da região em produzir imagens de si tensionando as anteriormente produzidas no período colonial, também delimita a compreensão desse cinema a partir de uma lógica territorial: em termos de origem dos seus cineastas, locação dos filmes e a expectativa por narrativas relacionadas àquilo que se apresenta (ou é convencionado) como "cultura africana" - expressão não menos sujeita a ambiguidades. Apesar das limitações que tal lógica conceitual pode apresentar, sobretudo diante da diversidade de filmes africanos na contemporaneidade, ela acabou se tornando a base para a compreensão inicial dessas produções, em virtude do contexto político que antecede o surgimento dos primeiros filmes de cineastas nascidos na África.

Apesar da naturalização dessa expressão, a sua utilização em termos conceituais e analíticos é limitada, pois além de não ter a capacidade de abarcar a diversidade de produções do continente, não contribui para uma emancipação analítica desses filmes, como se a sua pulsão criativa estivesse eternamente aprisionada ao comprometimento político que teria impulsionado a sua origem. Ou ainda, reduzindo a sua potencialidade política a determinadas convenções cinematográficas.

Alexie Tcheuyap em seu artigo "African cinema(s): definitions, identity and theoretical considerations" (2011a) afirma que não se pode falar de cinemas africanos partindo apenas da hipótese de que todos os diretores são politicamente comprometidos ou tem a necessidade de olhar para o passado. Novos gêneros, idiomas, formas e sistemas são explorados, e os próprios conceitos de nacionalidade, raça e política são revisados nas produções contemporâneas, o que demanda um novo olhar sobre esses cinemas. Assim: "[...] em um tal contexto, a concepção de 'cinema africano' como essencialmente político, ou tornado 'autêntico' por razões essencialistas, raciais, geográficas ou considerações culturais, torna-se problemática, se não controversa" (TCHEUYAP, 2011a, p. 11).

Com isso, não pretendemos trazer uma definição ou conceito definitivo para essas produções cinematográficas; antes destacamos esse fator conceitual por reconhecer que parte dos impasses correntes nas abordagens presentes tanto em festivais de cinema quanto em produções acadêmicas também podem ser um desdobramento dessa mediação conceitual dada pela expressão "cinema africano". Uma denominação que, na medida em que não é submetida a uma avaliação crítica em suas bases contextuais e históricas, limita a compreensão dessas cinematografias a um reduto conceitual incapaz de abarcar a diversidade da produção contemporânea. 


\section{Filmes africanos: abordagens}

O nigeriano Nwachukwu Frank Ukadike e o malinês Manthia Diawara, residentes nos Estados Unidos ${ }^{10}$, são precursores dos estudos publicados nesse país com um viés mais histórico sobre os cinemas africanos, priorizando em suas obras análises contextuais da economia, produção e distribuição de filmes no continente. African Cinema. Politics and Culture (DIAWARA, 1992) e Black African Cinema (UKADIKE, 1994) são os primeiros livros publicados sobre os cinemas africanos nos Estados Unidos, e ainda hoje as maiores referências no campo. Estas publicações acontecem em um contexto no qual os estudos de cinema baseados nas grandes teorias (historiografia, realismo e formalismo) começavam a ser questionados em favor de novas metodologias e teorias. Foi nesse momento que os Estudos Culturais avançaram e ganharam mais força, ao lado de estudos pós-coloniais e de gênero, de modo que a psicanálise, o estruturalismo e o pós-modernismo seriam abordagens convocadas para se pensar o cinema. Tais vertentes teóricas e abordagens metodológicas encontraram terreno fértil no universo dos temas trazidos pelos filmes africanos, estimulando a produção acadêmica de pesquisadores formados nas mais diversas áreas e que viam nesta jovem cinematografia material para pensar as questões que lhes interessava. Beatriz Leal Riesco (2014) comenta que esta tendência, resultado da formação literária dos pesquisadores, acabou por orientar a apreciação dos filmes africanos a partir de uma abordagem que com frequência ignorava não só a dimensão estética cinematográfica das obras, mas o contexto cinematográfico internacional do fenômeno que estavam estudando. Segundo Riesco, nessa época,

Urgia reconstruir a História, e os estudiosos se dedicaram a isso em suas obras iniciais, com um viés político progressista e de oposição usando narrativas históricas que agrupavam de maneira simplista cinematografias, filmes e autores por temas e orientação ideológica progressista. Das análises formais e das que situavam os cinemas africanos em escala global, se passaria rapidamente a leituras concretas psicanalíticas, pós-coloniais, de gênero e da pós-modernidade baseadas no mesmo corpus de filmes. [...] Poder-se-ia estar escrevendo sobre um romance, um quadro, uma obra de teatro ou um

\footnotetext{
10 Durante a escrita deste artigo, tivemos a notícia do falecimento do Nwachukwu Frank Ukadike, em 4 de agosto de 2018, quando visitava sua família na Nigéria. Referência nos estudos de cinemas africanos, Ukadike era professor da Universidade de Tulane nos Estados Unidos, e seu último livro publicado foi Critical Approaches to African Cinema Discourse, em 2014.
} 
filme, que o leitor não perceberia a diferença diante das críticas dos filmes individualmente"1 (RIESCO, 2014, p. 172-173, tradução nossa).

É importante contextualizar, no entanto, esta produção acadêmica de que fala Riesco. Com uma cinematografia muito jovem, se atribui aos anos de 1960 o início da produção cinematográfica africana pós-colonial - e desde então os realizadores têm de lidar com as expectativas dos festivais e dos pesquisadores e críticos europeus. Mais que isso, a produção intelectual sobre o cinema do continente, em sua maioria de autoria de pesquisadores europeus, durante muito tempo priorizou as abordagens apontadas por Riesco, que se sobrepuseram a uma análise estética que pudesse pensar o cinema como linguagem. Assim, se por um lado, os cineastas africanos tinham diante de si a oportunidade de representar a si mesmos, contribuindo para a política de libertação de seus países, em pouco tempo foram confrontados por novas fronteiras institucionais. Em livro no qual discute as motivações nacionalistas dos cinemas africanos e dos estudos sobre esta cinematografia, o autor camaronês Alexie Tcheuyap (2011b) relaciona a prática de estudos acadêmicos sobre os cinemas africanos com o discurso ideológico da Fédération Panafricaine des Cinéastes (FEPACl), instituição fundada em 1969 com base na ideologia de que o cinema deve servir à luta anticolonial e de forma alguma se render ao puro entretenimento - para eles, o cinema é um instrumento de luta através da educação ${ }^{12}$. Tcheyuap afirma que os pesquisadores pensam os filmes africanos a partir de uma oposição com o "ocidente homogêneo", o que acabou por influenciar grande parte das pesquisas das últimas décadas. Isso é interessante na medida em que, como acredita o autor, a produção acadêmica se viu tão obrigada a seguir os preceitos da $\mathrm{FEPACl}$ como os próprios cineastas - existe aqui uma aproximação intelectual entre pesquisadores e diretores. Essa relação imbricada, que resultou em uma corrente específica de estudos, com seus preceitos e objetivos no discurso, é o que Tcheuyap questiona ao longo dessa obra.

\footnotetext{
1 Do original: Urgía reconstruir la Historia, y en ello se aplicaron los estudiosos en sus obras iniciales, con un sesgo político progresista y de oposición usando unas narrativas históricas que agrupaban de manera sencilla cinematografías, películas y autores por temas y orientación ideológica progresista. Saltándose los análisis formales y aquellos que situasen a los cines africanos a escala global, se pasaría rápidamente a lecturas concretas psicoanalíticas, postcoloniales, de género y de la postmodernidad basadas en el mismo corpus de películas. [...] Se podría estar escribiendo sobre una novela, un cuadro, una obra de teatro o un filme, que el lector no se daría cuenta de la diferencia ante las críticas de las películas individuales.

12 No site oficial, a FEPACl se apresenta como uma organização que trabalha "incansavelmente ao longo dos anos colaborando e persuadindo os governos africanos e as organizações continentais, incluindo a União Africana, a reconhecer a importância das indústrias do cinema e do audiovisual na educação social, econômica e política das nossas populações, e a adotar políticas cinematográficas que estimulem o desenvolvimento do cinema em seus respectivos países, tanto continental como regionalmente" (FEPACl, 2018).
} 
Ele é categórico, inclusive, ao dizer que os pesquisadores abdicaram de suas responsabilidades intelectuais ao se limitar a apenas reproduzir o discurso da FEPACI nas suas análises sem minimamente questioná-lo³.

Em 1996 o jornalista e pesquisador francês Olivier Barlet publicou o livro Les cinémas d'Afrique noire: le regard en question, traduzido para o inglês em 2000 sob o título African Cinemas: decolonizing the gaze, no qual busca exercitar um olhar menos colonial e mais interessado em uma abordagem histórica sobre o contexto econômico e social de produção cinematográfica africana. Por mais que Barlet tenha se esforçado em pensar a cinematografia africana para além do olhar ocidental (o qual ele não se furta de ter), apresenta nesse livro análises mais contextuais e temáticas que estéticas - o que revela um imenso repertório e conhecimento dos filmes africanos e seus contextos de produção, mas pouca reflexão sobre as estéticas em si dos filmes convocados ${ }^{14}$. Outros pesquisadores ocidentais que se dedicaram a publicar sobre os cinemas africanos são Roy Armes (Reino Unido), David Murphy (Reino Unido), Melissa Thackway (Inglaterra/ França) e Françoise Pfaff (França). Em contrapartida, além de Manthia Diawara e Frank Ukadike, é certo que alguns pesquisadores africanos em diáspora estão ocupando posições de destaque no campo acadêmico do cinema e na pesquisa sobre os cinemas da África, a exemplo do supracitado Alexie Tcheuyap, residente no Canadá, após a publicação de Postnationalist African Cinemas (2011b).

Mahomed Bamba, em seu texto "O(s) cinema(s) africanos: no singular e no plural" (2008), comenta que é possível definir pelo menos dois tipos de abordagem predominantes desta cinematografia:

[...] os escritos teóricos terceiro-mundistas em que os filmes africanos são apenas incluídos numa discussão sobre o valor estético e político dos filmes produzidos em países periféricos com relação ao centro, consequência de um "redirecionamento" da teoria do terceiro cinema. Por outro lado, temos registros de cunho mais historicista, cujo interesse está exclusivamente nos filmes africanos e no seu contexto de produção, que tratam de fazer um paralelo entre a história do cinema

\footnotetext{
13 Para uma revisão de literatura com foco em como os principais autores do campo de estudos sobre os cinemas africanos orientaram suas pesquisas a partir do discurso ideológico da FEPACl, ver capítulo introdutório do livro Postnationalist African Cinemas (TCHEUYAP, 2011b).

14 Importante mencionar que Barlet é, antes de tudo, um crítico de cinema e em seus livros faz uma espécie de compilado de seus textos críticos publicados no site do qual é diretor, o Africultures, o que, por sua vez, demonstra um desdobramento do processo de retroalimentação entre crítica e academia no universo da cinematografia africana.
} 
africano e a história da descolonização da África pela apropriação da sua imagem (BAMBA, 2008, p. 217).

De fato, as primeiras pesquisas acadêmicas sobre os cinemas africanos surgem a partir dos estudos dos terceiros cinemas, começando por Questions of Third Cinema, de Jim Pine e Paul Willemen (1989), com artigos do cineasta Med Hondo, do professor etíope Teshome Gabriel, radicado em Los Angeles (falecido em 2010), e dos autores Paulin Vieyra e Manthia Diawara. Seus ensaios e discursos sobre o Terceiro Cinema foram os responsáveis pela "história dos cinemas africanos" e até hoje são tomados como referência, mesmo que com diferentes abordagens e com frequência revisados.

Justamente por se tratar de obras artísticas produzidas no contexto de outro continente, com cultura e formas distintas de compreender e representar o mundo, acreditamos que a análise de filmes africanos se caracteriza, pela maior parte dos críticos ocidentais, basicamente pelo desenho de três vertentes: uma mais voltada para a análise da representação contida nas narrativas e mais atenta ao discurso ideológico-político que se apresenta por meio dela, outra que se detém mais sobre a forma fílmica, os recursos técnicos e estilísticos utilizados pelo realizador, resultando muitas vezes em uma análise mais voltada para a autoria, e uma última que, inspirada no fenômeno de "Nollywood" esta específica cinematografia a partir de questões referentes às dinâmicas de produção, distribuição e espectatorialidade, especialmente em função de seu enorme alcance popular junto às plateias africanas, preterindo discussões sobre a estética e linguagem destes filmes. A escolha por uma vertente ou outra certamente é consequência de um processo de legitimação que acontece na retroalimentação que existe entre os festivais consagradores em nível mundial (como os de Cannes, Veneza, Berlim e Toronto, pra mencionar alguns), bem como aqueles especificamente voltados à curadoria de filmes africanos, e as instâncias da pesquisa acadêmica e da crítica em si. A interpretação atribuída aos filmes é, portanto, mediada por diferentes instâncias ou agentes que compõem o espaço de circulação das obras, e é através delas que se constituem também outras formas de mediação dos filmes africanos com o público.

\footnotetext{
15 Convencionou-se chamar de Nollywood a indústria de filmes na Nigéria, a segunda maior indústria em número de filmes produzidos por ano e a terceira em faturamento. A produção de filmes em Nollywood teve início nos anos 1990 e arrecada 250 milhões de dólares por ano, com filmes distribuídos em formato de vídeo/ DVD e com uma estética amadora, porém muito popular no país.
} 
A primeira vertente de abordagem pode ser considerada como um possível desdobramento da militância atribuída a essa produção cinematográfica, fruto do contexto de pós-independência que marcou o surgimento dos primeiros filmes africanos, no contexto da fundação da FEPACl, como mencionado anteriormente. Tal abordagem tende a avaliar as obras sob o prisma de discussões relacionadas à identidade cultural, pós-colonialismo, imigração - temas que, embora tenham pertinência com a narrativa, podem conduzir a discussões que em geral ultrapassam o que é relativo à estética do filme, sua linguagem específica e sua compreensão enquanto produção artística. Esse conflito na forma de abordagem na interpretação de filmes é bem assinalado por Robert Stam (2000) quando discute questões de multiculturalismo, raça e representação no cinema:

A priorização da representação social, da trama, da personagem leva com frequência a uma negligência das dimensões cinematográficas específicas dos filmes; seguidamente, as análises poderiam ter sido simplesmente de romances ou peças. Uma análise rigorosa tem de estar atenta às 'mediações': a estrutura narrativa, as convenções genéricas, o estilo cinematográfico". [...] Se, por um lado, o cinema é mimese e representação, por outro, é também enunciado, um ato de interlocução contextualizada entre produtores e receptores socialmente localizados. Não basta dizer que a arte é construída. Temos de perguntar: construída para quem e que conjunção com quais ideologias e discursos? (STAM, 2000, p. 304-305, grifo nosso).

A não problematização dos critérios envolvidos nas escolhas metodológicas de análise de filmes africanos pode ter, pelo menos, duas consequências: a interpretação do filme como pretexto para discussão de questões extra-fílmicas ou, pela hegemonia de determinados métodos e procedimentos de análise, impedir que outras leituras deem conta da pluralidade formal e estética desta cinematografia. Por se tratar de um cinema oriundo de países de outro continente, resultante de uma configuração histórica e social muitas vezes distinta e distante de quem analisa, a interpretação de filmes africanos não raro está suscetível a uma leitura com direcionamento político-ideológico. Isso se aplica, por exemplo, às análises feitas por críticos brasileiros que, pela afinidade histórica de pertencer a um país colonizado - à semelhança de quase todos os países africanos - tendem a construir um discurso interpretativo da obra fílmica pautado em questões de busca de identidade, emancipação política etc. Mahomed Bamba, ao tratar da relação entre cinemas africanos e modernidade, confessa o seu incômodo com 
a predominância de uma determinada perspectiva de julgamento dos filmes: "Os horizontes de expectativas dos públicos brasileiros e da diáspora negra às vezes me confrontavam numa leitura demasiadamente temática e 'culturalista' dos conteúdos fílmicos" (BAMBA, 2009, p. 183). Mais adiante, no mesmo texto, o pesquisador não só ratifica sua oposição a esse posicionamento crítico como propõe uma alternativa para a análise dessas cinematografias:

Ora, fazer da obra de um autor o reflexo de uma realidade nacional incorre sempre no erro de desconsiderar a 'intencionalidade' e a subjetividade que são uma dimensão constitutiva de qualquer processo de criação. [...] Ao questionar o culturalismo automático que vigora na análise dos filmes africanos, minha intenção é postular uma diversidade de grades de leitura que permitissem a emergência de outros percursos de sentidos (BAMBA, 2009, p. 185).

Fica evidente, portanto, que as três vertentes de abordagem analítica, que podemos chamar de "culturalista", "autoral" e de "produção", têm os seus devidos agentes, precedentes históricos e modos de legitimação, e através das discussões relacionadas aos processos de mediação implicados nos discursos sobre os cinemas africanos, pretendemos compreender como elas se organizam, a partir de que horizonte de expectativas, e como dialogam com os espaços de comunicação delimitados pelos festivais de cinema e pela produção acadêmica. Para tanto, voltaremos nosso olhar para os discursos produzidos no Brasil em datas recentes, no âmbito dos catálogos de mostras de filmes africanos que aconteceram no país. Consideraremos os textos analíticos publicados nos catálogos das mostras África, Cinema - Um Olhar Contemporâneo (2015), África(s) - Cinema e Revolução (2016) e Grandes Clássicos dos Cinemas Africanos (2017), todas produzidas pela Caixa Cultural, o que nos permitirá trabalhar sobre um escopo minimamente exemplar do que propomos no âmbito deste artigo.

\section{Das abordagens analíticas dos cinemas africanos}

Durante muitos anos, a produção de imagens das diferentes realidades da África foi refém de uma perspectiva eurocêntrica para a qual restava um olhar compassivo sobre o "outro" colonizado, espoliado. À medida que os meios de produção cinematográficos se difundiram entre realizadores africanos, especificamente a partir dos anos 1960, quando do início das independências, tratar da cultura local a partir de valores nacionalistas parecia uma causa relevante para 
(re)construir a história negada pelo outro colonizador ${ }^{16}$. No entanto, por efeito do processo de globalização, ocorrem transformações estruturais no campo do cinema mundial, tanto na produção com as novas lógicas de coprodução, quanto na recepção com a emergência de novos espaços de circulação das obras em lugar dos tradicionais circuitos: "Nesses espaços, operam outras formas de mediação e outros tipos de determinações institucionais no processo de apropriação e de leitura dos filmes" (BAMBA, 2013, p. 220).

Não raro a análise e crítica feitas sobre filmes se ampara em uma lógica de aplicação instrumental da teoria, não levando em conta os precedentes históricos das teorias e suas implicações no processo de recepção/circulação dos filmes. Desde o início da produção cinematográfica africana pós-colonial cineastas como Ousmane Sembène (Senegal) e Med Hondo (Mauritânia) encontravam-se à mercê das instâncias de consagração do cinema, especialmente da França. Muitos dos seus filmes foram frutos de uma longa jornada para conseguir financiamento da antiga colônia ${ }^{17}$, e sua exibição e premiação em festivais estava condicionada à aceitação, por parte dos curadores, da abordagem temática apresentada pelos filmes. A despeito da inegável qualidade técnica e narrativa de filmes como $L a$ noire de... (1966, de Ousmane Sembène) e Soleil Ô (1967, de Med Hondo) - para citar apenas os primeiros longas-metragens destes diretores - os curadores levavam em consideração primeiramente a história contada e a ideologia por trás de narrativas anticoloniais. Dos filmes "combativos" de Sembène e Hondo se sobrepuseram aqueles de realizadores como o malinês Souleymane Cissé e o burquinense Idrissa Ouedraogo, que apresentavam, respectivamente, narrativas com uma abordagem mais focada na África tradicional, mítica e atemporal, e no olhar poético e nostálgico do africano em diáspora sobre sua terra natal. Filmes como Finye (1982) e Yeelen (1987), ambos de Cissé, foram celebrados em Cannes, bem com Yaaba (1989) e Tïlai (1990), de Ouédraogo. Na nova geração de realizadores, podemos citar o mauritano Abderrahmane Sissako, cuja filmografia completa teve sua estreia neste festival' ${ }^{18}$.

\footnotetext{
16 Para uma abordagem histórica sobre quando os africanos se apossaram dos instrumentos e da técnica para fazer filmes, em um contexto onde a produção de filmes era totalmente voltada para interesses coloniais, ver Manthia Diawara (1992). Para uma revisão crítica mais aprofundada sobre a história crítica/acadêmica dos cinemas africanos, ver Melissa Thackway (2003).

17 Cf. Diawara (1992).

18 Filmes de Sissako que estrearam no Festival de Cannes: Octobre (1993) e Heremakono (2002), ambos na seção Un certain regard, Bamako (2006), exibido fora de competição e Timbuktu (2014) que integrou a competição de longa-metragens. Disponível em: http://www.festival-cannes.com/en/artist/abderrahmane-sissako. Acesso em: 26 jul. 2018.
} 
De uma forma ou de outra, celebradas ou evitadas pelas instâncias europeias de consagração, as obras destes cineastas, com o passar dos anos, foram objeto de profundas investigações acadêmicas sobre seus conteúdos políticos e sua importância na história dos cinemas africanos e do próprio continente. Mesmo com a existência de um cinema popular e de gênero na África, que viria a ganhar força a partir dos anos 1990, especialmente na Nigéria, são as cinematografias autorais que ganham legitimidade no espaço acadêmico, pois essas obras correspondem, de certa forma, às categorias teóricas já elaboradas no campo e confirmam as expectativas de alguns críticos e estudiosos franceses e norte-americanos. Assim é que:

Os principais periódicos de cinema começaram a dedicar dossiês inteiros aos cinemas africanos a partir dos anos 1990, isto é, quase no mesmo período em que alguns cineastas africanos como Cissé, Ouedraogo entre outros despontavam e angariavam reconhecimento e prêmios da crítica especializada pelos tipos de cinema de autor que vinham propondo (BAMBA, 2013, p. 228).

É importante mencionar que o fenômeno "Nollywood" ganhou muita importância na academia, especialmente nos Estados Unidos. As discussões, no entanto, se desdobraram em temas voltados à produção e à espectatorialidade, como já mencionado aqui brevemente, com análises que buscavam entender o surgimento e a atuação de uma indústria autossustentável em um único país africano, e que hoje atua em diversos países do continente como Gana, Uganda, República Democrática do Congo, Camarões, Níger e Benin ${ }^{19}$. O primeiro autor a abordar historicamente o fenômeno chamando-o de "Nollywood" foi o jornalista francês Pierre Barrot publicado no livro Nollywood: Le phénomène vidéo au Nigeria (2005, traduzido para o inglês em 2008), ao qual se seguiram muitos outros como: Nollywood (Pieter Hugo e Chris Abani, 2009), Global Nollywood: the transnational dimensions of an African Video Film Industry (Matthias Krings e Onookome Okome, 2013), Nollywood: the creation of Nigerian Film Genres (Jonathan Haynes, 2016), Nollywood: popular culture and narratives of youth struggles in Nigeria (Paul Ugor, 2016), Nollywood Central: the Nigerian Videofilm Industry (Jade L. Miller, 2016),

\footnotetext{
19 Para uma discussão sobre o termo "Nollywood" e a referência que faz à indústria cinematográfica estadunidense, bem como uma análise de como a produção de filmes na Nigéria constrói a sua própria lógica estética, cultural e de mercado, e dialoga com as tendências contemporâneas de espectatorialidade no país e no âmbito da diáspora, recomenda-se a leitura do artigo "Stop comparing Nollywood to Hollywood: reorienting western understanding of Nigerian cinema" (SCHNELL, 2017).
} 
Nollywood: the making of a film empire (Emily Witt, 2017), além de inúmeros artigos publicados inclusive em dossiês dedicados exclusivamente ao tema, como o Journal of African Cinemas, volume 6, número 1, publicado em 1 de abril de 2014. Como desdobramento, também surgiram muitos festivais pelo mundo dedicados exclusivamente à "Nollywood": NollywoodWeek Paris, Toronto International Nollywood Film Festival (TINFF), Nollywood Travel Film Festival (itinerante), Nollywood Film Festival Germany e New York Nigerian Film Festival ${ }^{20}$.

De forma semelhante às publicações de textos críticos, como revistas científicas, sites de crítica ou catálogos de mostras, os festivais de cinema europeus acabam funcionando como um parâmetro de avaliação internacional dos cinemas africanos de modo que aparecer na lista de filmes selecionados para o Festival de Cannes, por exemplo, significa que a produção não só foi bem-sucedida no ano da sua indicação como tem aumentadas suas chances de exibição em outros festivais, e de distribuição internacional. Segundo a pesquisadora britânica Lindiwe Dovey (2015) em seu livro sobre os festivais de cinemas africanos, eles começaram a surgir fora da África a partir de $1979^{21}$ inspirados principalmente no FESPACO - Festival Panafricano de Cinema e Televisão (Burkina Faso), o primeiro e mais importante festival de cinema africano do mundo, mantendo seu destaque até hoje. Dovey aponta que a proliferação destes festivais, especialmente na Europa ocidental, pode ser compreendida de duas formas:

[...] primeiro, em relação à política representacional em torno do conceito de "África" (particularmente como fazendo parte dos principais festivais de cinema e da imprensa mainstream); e, segundo, em relação à crescente presença de diversas diásporas africanas na era pós-Segunda Guerra Mundial. Em outro sentido, esses festivais também podem ser lidos alternadamente como reações a minorias imigrantes africanas, bem como suas expressões (DOVEY, 2015, p. 111, tradução nossa) ${ }^{22}$.

\footnotetext{
20 Este último se encontra mais ancorado no atual estágio de pesquisa sobre a produção cinematográfica na Nigéria, que está para além da estética amadora e do mercado de DVDs, e mais focado no que atualmente se chama New Nollywood: filmes um pouco mais preocupados com a qualidade da produção e os box offices dentro e fora da África. Exemplos destes filmes são: Fifty (2015, de Biyi Bandele), Out of Luck (2015, de Niyi Akinmolayan) e The Wedding Party (2016, de Kemi Adetiba), todos com financiamento em coprodução de diversos investidores nigerianos, com estreia e distribuição internacional, e com contratos de licenciamento assinados com a plataforma Netflix para vários países do mundo, inclusive o Brasil.

${ }^{21}$ A autora oferece uma lista bastante completa destes festivais no apêndice desta sua publicação.

22 Do original: [...] first, as relating to representational politics around the concept of "Africa" (particularly as curated into being through "A-list" film festivals and the mainstream news media); and, second, as relating to
} 
Desta forma, também passaram a funcionar como alternativas à ausência de uma política cinematográfica nos países do continente e contribuíram de forma significativa para amenizar a deficiência de distribuição e circulação de filmes africanos entre as populações ocidentais.

\section{Da retroalimentação entre festivais e academia}

Em artigo sobre a mostra Malembe ${ }^{23}$, Mahomed Bamba traz o tema da recepção de filmes africanos em pequenas mostras e festivais no Brasil. Segundo ele, mostras como essas revelavam "práticas de apropriação simbólica em que os filmes eram apreciados mais por seu valor cultural do que puramente estético" (BAMBA, 2010, p. 1). Segundo ele "diversos fatores sócio-políticos circunstanciais acabam incidindo na recepção dos cinemas africanos, a ponto de criarem, às vezes, uma descontinuidade e fratura entre os horizontes de expectativas e as 'intenções' inerentes à produção das obras fílmicas" (BAMBA, 2010, p. 1). A preocupação (ou o "incômodo") do autor vai ao encontro da nossa discussão proposta aqui, no momento em que coloca em perspectiva quais disputas envolvendo curadoria, exibição e recepção dos filmes africanos em espaços de comunicação específicos como mostras. Bamba volta o olhar especificamente sobre os catálogos, produção analítica resultante desta curadoria específica.

\footnotetext{
Os catálogos e encartes das mostras de cinemas são ilustrativos das intenções e lógicas que motivam a seleção criteriosa do acervo de filmes em exibição. A seleção dos filmes em uma mostra ou festival de cinemas estrangeiros se funda, em muitos casos, numa lógica estético-ideológica. As obras oferecidas à apreciação dos públicos valem pelo que representam de tradicional ou inovador em termos artísticos. Mas podem estar na programação pelo seu valor cultural. Foi em virtude desta lógica de interpretação que os cinemas africanos, desde sua emergência até hoje, continuam encontrando seu maior número de público fora de seu contexto cultural de produção, isto é, nos próprios países africanos (BAMBA, 2010, p. 5-6).
}

\footnotetext{
the increasing presence of diverse African diasporas in the post-WWII era. In the latter sense, these festivals can also be read alternately as responses to, and expressions of, African immigrant minorities.

23 Mostra que orientava a exibição dos filmes africanos dentro de um conjunto de ações estratégicas que visavam a implementação da lei de obrigatoriedade do ensino da história e cultura afro-brasileira e africana no Ensino Fundamental e Médio (Lei 10.639/03). A mostra teve três edições, duas das quais realizadas nos estados de Santa Catarina (2009) e Amazonas (2007).
} 
Acreditamos que a inserção dos filmes africanos nesses espaços é fruto de uma construção discursiva que ocorre no campo acadêmico. Essas duas instâncias (ou espaços de comunicação) se autorreferendam e legitimam, logo a escolha de uma abordagem específica de interpretação da obra fílmica a partir de um viés mais autoral, por exemplo, acaba tendo sua origem no imbricamento destes discursos e, ao fim, funciona também como uma estratégia de mediação e negociação com esses espaços. Tanto é que não raro a curadoria de mostras e festivais e a atuação acadêmica coincidem sobre a mesma pessoa, assumindo elas mesmas o lugar de sujeitos dessas mediações.

Como exemplos, o pesquisador Guido Convents, autor do livro L'Afrique? Quel cinéma! Un siècle de propagande coloniale et de films africains (2003), é um dos organizadores do Afrika Filmfestival (AFF), de Louvain (Bélgica); Joel Zito Araújo, cineasta e pesquisador, foi responsável pela curadoria do Encontro de Cinema Negro Zózimo Bullbul, no Rio de Janeiro (Brasil), entre outros. O festival Africa in Motion (AIM), realizado em Edimburgo (Escócia), tem curadoria de Lizelle Bisschoff, professora da School of Culture \& Creative Arts da University of Glasgow (Escócia), especialista em diversas questões relacionadas aos cinemas africanos, e o Film Africa (Londres) foi cofundado por Lindiwe Dovey, pesquisadora dos cinemas africanos e professora da SOAS, University of London. Dovey também é cofundadora do Cambridge African Film Festival, que teve sua 17. edição em 2018. Estes são só alguns dos inúmeros exemplos de como os festivais e a academia são duas instituições que se retroalimentam e constroem, portanto, determinados discursos que servem como mediadores com o público dos cinemas africanos. Este padrão se repete nas três edições de mostras realizadas com o patrocínio da Caixa Cultural nos estados de São Paulo e Rio de Janeiro, de 2015 a 2017, que consideramos aqui para tentar compreender como os curadores realizam essa mediação através do texto de apresentação dos catálogos e dos filmes selecionados para exibição.

O catálogo da mostra "África, cinema: um olhar contemporâneo" (2015) foi organizado pelo crítico e cineasta Leonardo Luiz Ferreira ${ }^{24}$ e realizada sob a curadoria de João Juarez Guimarães, que apresenta o evento nas seguintes palavras no texto editorial:

24 Leonardo Ferreira é diretor de cinema e já realizou filmes como Orestes (2015) e Chantal Akerman, de cá (2011), além de ter participado como membro do júri do $33 .{ }^{\circ}$ Festival internacional do Novo Cinema Latino Americano (Havana, 2011) e do 7. ${ }^{\circ}$ Festival Internacional do Rio de Janeiro (2005). 
A mostra África, Cinema - Um Olhar Contemporâneo vai apresentar ao público carioca películas recentes de cineastas de países como Burkina Faso, Congo, Chade, Mali, Mauritânia, Moçambique e Senegal. O mauritano Abderrahmane Sissako e o chadiano MahamatSaleh Haroun, que já tiveram Timbuktu e Um Homem que Grita em exibição comercial no Brasil, são os mais reconhecidos autores da região e recebem uma seleção especial de seus longas no evento (GUIMARÃES, 2015, p. 7).

Desde a sua apresentação a mostra justifica a escolha dos cineastas fazendo referência à suas obras autorais. A chamada dos filmes se dá a partir de realizadores específicos de cada país listado (apenas Moçambique aparece entre os países da África de língua portuguesa, o que atesta um destaque para a cinematografia francófona trazida pela mostra) ${ }^{25}$, tomando como referência o trabalho autoral de nomes como Abderrahmane Sissako e Mahamat-Saleh Haroun. Ao mencionar que estes são "os mais reconhecidos autores da região", o curador da mostra, apesar de não especificar que reconhecimento é este ${ }^{26}$, reitera que os critérios estão baseados na legitimidade destes cineastas em determinados espaços de visibilidade.

O catálogo conta com cinco críticas aos filmes pertencentes à mostra, uma compilação de textos publicados anteriormente em sites de críticas brasileiros, além de dois artigos acadêmicos (um sobre o projeto político do cinema africano e outro de natureza panorâmica sobre a história desta cinematografia), uma entrevista com um autor referência nos estudos desta área (Manthia Diawara) e um perfil do cineasta Licínio Azevedo. Guimarães oferece uma pista sobre o que considera contemporâneo nos cinemas africanos ao mencionar a qualidade dos filmes:

Os títulos apresentados na mostra África, Cinema - Um Olhar Contemporâneo impressionam pela inteligência e criatividade com que transpõem a cultura de seus países para a tela e derrubam por terra a crítica de que o cinema africano peca pelo amadorismo e deficiências técnicas. Suas obras com narrativas originalíssimas e sedutoras são realizadas com esmerado acabamento (GUIMARÃES, 2015, p. 7).

\footnotetext{
25 Dos 16 filmes que compuseram a mostra, apenas um era de língua portuguesa (Virgem Margarida, de Licínio Azevedo, Moçambique, 2012), sendo a filmografia de Mahamat-Saleh Haroun o grande destaque compondo seis títulos dentro da programação.

26 Há uma pista sobre o que seriam essas instâncias de reconhecimento ao mencionar o fato de pelo menos um filme de cada diretor (Haroun e Sissako) já ter tido distribuição comercial no Brasil. Em entrevista com o pesquisador Manthia Diawara, publicada no mesmo catálogo, há outra menção a este ser o critério que define estes dois cineastas como "destaques" do cinema africano no Brasil. Cf. Ferreira (2015, p. 44).
} 
Como discutimos acima, a questão da cultura local é sempre um ponto a ser considerado na atividade curatorial, bem como a tentativa de refutar pressupostos como a crença de que o cinema africano é amador e falho tecnicamente, e nada sedutor ou original. Se considerarmos o conjunto de textos pertencentes a esse catálogo, as vertentes "autorais" e "culturalistas" apresentam-se com destaque, a começar pelas críticas publicadas, as três primeiras sobre filmes do Mahamat-Saleh Haroun, em um discurso que insiste em consagrar uma obra a partir do seu autor e da temática social e política construída como discurso em seus filmes. Em um trecho da crítica Resquícios de beleza, escrita por Heitor Augusto sobre o filme Grigris, o autor afirma ser Haroun:

[...] o melhor realizador africano da atualidade e representante solitário da cinematografia chadiana, cuja dependência da antiga metrópole para a produção e do selo legitimador dos festivais europeus tornam ainda mais complexo falar de identidade local e autenticidade - um senão bastante comum no continente (AUGUSTO, 2015, p. 18).

À obsessão dos críticos pela autoria se soma o fetiche pela "autenticidade", questionada de modo muito pertinente pelo escritor moçambicano Mia Couto em uma de suas conferências publicadas em texto ${ }^{27}$. A crítica publicada nesse mesmo catálogo sobre o filme Timbuktu, do Sissako, desde o título já convoca as questões que considera relevantes: "Cantos e uivos de resistência". De autoria de Pablo Gonçalo, a crítica elabora seus comentários a partir da história contada no filme, e o que parece importar na obra é o discurso de "resistência" convocado desde o início do texto, o que de alguma forma se alastra para o texto seguinte, "Frustração e esperança", de autoria de Rafael Saraiva, sobre o filme $O$ barco da esperança (2012), do senegalês Moussa Touré. A crítica do autor também está centrada na questão social trazida pelo longa, com comentários muito breves para além do enredo. Em comum a todos os textos existe uma disposição em apontar problemas de interpretação dos atores, bem como suas entonações, ignorando talvez a sonoridade própria das línguas nativas às quais o ocidente não está acostumado. Já o artigo intitulado "O cinema político africano e o direito

${ }_{27}$ Nessa conferência, o escritor propõe um questionamento sobre a obrigação da autenticidade imposta aos artistas e intelectuais do continente africano. Sob o título "Que África escreve o escritor africano" (COUTO, 2005), o autor toma como gancho a nova literatura africana para fazer uma crítica à ideia de "africanidade" como algo absoluto, fluido e fácil de definir. Para o autor, é urgente que se pense a África a partir de questões ao mesmo tempo próprias e universais, e que os africanos não tenham medo de renegar a importância, estabelecida pelo colonialismo e tomando este como referência, de ser "autêntico". 
de narrar", de Marcelo Rodrigues Souza Ribeiro, busca destacar esta que é uma questão quase que superada, porque já bastante discutida e por ser quase um $a$ priori, na literatura sobre os cinemas africanos, ao mesmo tempo em que reitera a proposta muito marcada desta Mostra: construir discursos interpretativos que compreendem esta cinematografia como autoral, engajada e autêntica.

Já a mostra "África(s): cinema e revolução" (2016) foi realizada em São Paulo sob a curadoria de Lúcia Ramos Monteiro, doutora em cinema pela Universidade Sorbonne Nouvelle Paris 3 e pela Universidade de São Paulo, que em 2016 assinou o editorial de um dossiê dedicado aos cinemas africanos na Revista Rebeca ${ }^{28}$ e na Revista África(s) ${ }^{29}$. No catálogo da Mostra a programação é apresentada nos seguintes termos:

As questões levantadas pelos filmes reunidos nesta mostra devem encontrar eco no contexto brasileiro atual, em que as discussões sobre negritude, racismo, identidade cultural e engajamento na arte conquistam espaço e ganham contorno (MONTEIRO, 2016, p. 14).

Dos 36 filmes selecionados, a maioria era de países como Angola, Moçambique e Guiné-Bissau que, assim como o Brasil, foram colônias portuguesas, o que por vezes mobiliza a realização de paralelos e comparativos em termos políticos. O catálogo da mostra publicou vinte textos de pesquisadores de diversas áreas do conhecimento, e em geral os artigos versam sobre questões relacionadas ao contexto pós-colonial trazidas pelos filmes em exibição. Com quase 200 páginas, o catálogo reúne artigos assinados por pesquisadores, dedicando apenas dez páginas às sinopses dos filmes exibidos na mostra com curadoria voltada para países africanos de língua portuguesa e seu diálogo com o Brasil. Com um viés histórico, esta Mostra teve um perfil de panorama relacionado a um momento e região específicos.

A mostra mais recente, "Grandes clássicos do cinema africano" (2017), organizada sob a curadoria de Tiago Castro Gomes ${ }^{30}$, focou em produções realizadas

\footnotetext{
28 Rebeca - Revista Brasileira de Estudos de Cinema e Audiovisual, v. 5, n. 2, Sociedade Brasileira de Estudos de Cinema e Audiovisual - Socine, jul./dez. 2016. O dossiê - Africanidades foi organizado por Lúcia Monteiro e Amaranta César.

29 Revista África(s), v. 4, n. 7, jan./jun. 2017. Revista do Programa de Pós-Graduação em Estudos Africanos, Povos Indígenas e Culturas Negras - PPGEAFIN da Universidade do Estado da Bahia - UNEB.

30 Tiago Castro Gomes tem seus trabalhos de graduação e de mestrado na área de cinema com foco nos cinemas africanos. Um breve olhar sobre os resumos da sua monografia e dissertação revela a preocupação que o pesquisador tem em pensar os cinemas da África a partir de uma discussão voltada para questões mais históricas com relação à produção e economia dos filmes africanos: Ousmane Sembène e o(s) cinema(s) da África (Monografia, 2013), "Para africano ver": Cinema na África Colonial Britânica - de sua consolidação
} 
na África Ocidental Francófona Subsaariana, nas décadas de 1950 a 1970, por ser, segundo ele, o início de uma produção "essencialmente africana" (GOMES, 2017, p. 3), logo após a independência de diversos países. Aqui temos mais uma mostra que se baseia na historiografia que organiza a produção fílmica da África com base no processo político de independência de seus países, o que, por consequência, vai se desdobrar nesta vertente dos filmes selecionados. Apesar de fazer dois recortes bem específicos (países de língua francesa ao sul do Saara e filmes realizados em um determinado período de efervescência política), o texto de apresentação acaba restringindo a compreensão dos filmes a uma determinada abordagem:

Em todos os textos apresentados, o que se apreende é que o cinema produzido nos países localizados no sul do Saara na África Ocidental Francófona foi e continua sendo considerado um meio ativo, definidor de identidades e interrogador da realidade (GOMES, 2017, p. 11).

Os textos publicados nesse catálogo revelam mais uma vez um perfil de pensar os filmes africanos a partir da questão pós-colonial, especialmente a partir de uma metodologia de análise que considere esses temas em obras de cineastas específicos. É pertinente observar nos exemplos destas três mostras o que elas consideram como "clássico", "contemporâneo" e "revolucionário". Apesar de seus textos de apresentação não assumirem, as mostras têm não somente um caráter panorâmico que é de sua natureza, mas acabam funcionando como vitrines de apresentação dos cinemas africanos para públicos potencialmente leigos. Em comum aos discursos produzidos pelas três mostras está a definição de critério de legitimidade à obra autoral e a relevância temática dos filmes no que diz respeito ao projeto político que marcou o início da produção cinematográfica africana pós-colonial.

\section{Considerações finais}

Em uma edição especial da revista Cinema Journal - The Journal of the Society for Cinema \& Media Studies (University of Texas Press) em 2015, houve uma proposta de reunir artigos que pensassem a relação entre cinemas africanos e dispositivos midiáticos, uma das preocupações que vem instigando a produção acadêmica deste campo, especialmente nos Estados Unidos. Intitulado In Focus: Studying 
African Cinema and media today, o dossiê apresenta um texto introdutório, de autoria de Aboubakar Sanogo (também editor da publicação), que compila de forma bastante pertinente as tendências discursivas empregadas para a análise dos filmes africanos. Segundo ele, o campo de estudos dos cinemas africanos ainda dá voltas ao redor da dúvida que paira sobre os pesquisadores sobre qual seria o modo apropriado de abordar o tema tendo em vista a dialética entre sua generalização e contingência, o que significa que a teoria (ou a teorização) desta cinematografia precisa antes dar conta de resolver se o cinema africano é um cinema como qualquer outro e se, portanto, deve ser tratado como tal. A partir deste dilema, o autor levanta questões que considera pertinentes no sentido de entender como esse universo fílmico tem sido estudado pela academia:

Qual é ou pode ser a relação do cinema africano como objeto e conjunto de práticas com a chamada teoria "ocidental"? É ou deveria ser considerado em termos do vampirismo da teoria aplicada, da violência epistêmica, da "matéria-prima" a ser processada pelo logos da teoria "ocidental", ou deveria, ao contrário, ser visto como um diálogo mutuamente benéfico? A teoria "ocidental" poderia oferecer uma visão útil para o estudo do cinema africano? Por outro lado, estudos em cinema africano e mídia poderiam ajudar a descartar pressupostos e aporias na chamada teoria "ocidental", ela mesma indevidamente substanciada e apresentada como autotélica? (SANOGO, 2015, p. 115).

Como vimos, a escolha de abordagem teórica e analítica dentro do universo da academia em muitos casos resulta do reconhecimento das obras pelos festivais, uma vez que seus discursos podem não somente ser condicionados pelas mostras, mas servem também como referência para seus processos de curadoria. A academia e os festivais e mostras de cinema trabalham, portanto, em um intenso processo de retroalimentação - o que influi diretamente sobre como os filmes africanos serão vistos pelas audiências tanto dos festivais quanto da academia, considerando que são estes ainda os seus principais públicos. Como exemplo, as análises são focadas nos aspectos autorais das narrativas fílmicas, tendência que, enquanto discurso, visa ajustar a avaliação da obra aos parâmetros adotados em festivais internacionais europeus como o de Cannes, Veneza e Berlim, por exemplo, espaços onde o cinema de autor ainda é bastante cultuado.

Ao mesmo tempo em que a cinematografia produzida procurava se adequar às expectativas dos festivais, os processos de leitura mais temática predominante nas curadorias, ao enfatizar a "função desmistificadora" dos filmes selecionados, 
continuaram a adotar como chave de interpretação fílmica o aspecto anticolonialista e pós-colonial das narrativas. Apesar dessas diferentes abordagens, ora enfatizando o autor, ora a temática representada, as interpretações predominantes no Brasil continuam sendo aquelas geradas a partir dos discursos produzidos e mantidos pelas instituições que sustentam a cinematografia africana: os festivais e a academia. É importante acrescentar aqui a importância de instituições como, por exemplo, a Aliança Francesa (através do Instituto Francês e das Embaixadas da França em vários países pelo mundo) e o Goethe-Institut, que anualmente investem valores consideráveis para a suposta promoção da cultura africana através de iniciativas como preservação e distribuição de filmes via cinemateca, passando por apoio financeiro via parceria com produções locais, até programas de residência artística que permitem que artistas africanos circulem entre países diversos em intercâmbio. Importante também observar o fato de o tema "cinema africano" notadamente ser do interesse de iniciativas de financiamento de instituições públicas e privadas, como no caso da patrocinadora de todas as mostras brasileiras analisadas aqui (e de outras ainda antes dessas).

O que nos interessou provocar com este artigo dialoga com as inquietações de Sanogo (2015) no texto supracitado. O que de fato significa estudar os cinemas africanos e como as diversas abordagens analíticas implicam diretamente na vida útil destes filmes? Para o autor, estudar a relação entre cinemas africanos e a mídia hoje "implica em reconhecer a contingência radical do legado do campo geral dos estudos de cinema e mídia, muitas vezes propensos a generalizações" (SANOGO, 2015, p. 119), e esse é um desafio que se coloca para todos que desejam dialogar com o universo desta cinematografia.

\section{Referências}

AUGUSTO, Heitor. Grisgris: resquícios de beleza. In: FERREIRA, Leonardo Luiz. (org.). África, cinema: um olhar contemporâneo. Rio de Janeiro: Laffilmes Cinematográfica, 2015.

BAMBA, Mahomed. O(s) cinema(s) africano(s): no singular e no plural. In: BATISTA, Mauro; MASCARELLO, Fernando (org.). Cinema mundial contemporâneo. Campinas, SP: Papirus, 2008.

BAMBA, Mahomed. Que modernidade para os cinemas africanos? FórumDoc. $\mathrm{BH}-13^{\circ}$ Festival do Filme Documentário e Etnográfico / Fórum de Antropologia, Cinema e Vídeo, 2009, p. 183-189.

BAMBA, Mahomed. Cinema e recepções transnacionais: estudos das práticas de apropriação simbólica em duas mostras de cinemas africanos no Brasil: Florianópolis e 
Manaus. VI ENECULT - ENCONTRO DE ESTUDOS MULTIDISCIPLINARES EM CULTURA. Anais... Salvador, UFBA, 2010.

BAMBA, Mahomed. Os espaços de recepção transnacional dos filmes: propostas para uma abordagem semiopragmática, Revista Crítica Cultural, v. 8, n. 2, p. 219-237, 2013. https://doi.org/10.19177/rcc.v8e22013219-237

BARLET, Olivier. African cinemas: decolonizing the gaze. London: Zed Books, 2000.

DIAWARA, Manthia. African cinema: politics \& culture. Bloomington, Indianapolis: Indiana University Press, 1992. https://doi.org/10.1163/18757421-90000201

DOVEY, Lindiwe. Curating Africa in the age of film festivals. New York: Palgrave Macmillan US, 2015. https://doi.org/10.14361/zkmm-2017-0214

FEPACI. FEPACI - About us. Disponível em: http://www.fepacisecretariat.org/about-us/. Acesso em: 26 jul. 2018.

FERREIRA, Leonardo Luiz (org.). África, cinema: um olhar contemporâneo. Rio de Janeiro: Laffilmes Cinematográfica, 2015.

GOMES, Tiago Castro (org.). Grandes clássicos do cinema africano. Rio de Janeiro: Insensatez Audiovisual, 2017.

GUIMARÃES, João Juarez. Editorial. In: FERREIRA, Leonardo Luiz (org.). África, cinema: um olhar contemporâneo. Rio de Janeiro: Laffilmes Cinematográfica, 2015.

MONTEIRO, Lúcia Ramos (org.). África(s), cinema e revolução. São Paulo, SP: Buena Onda Produções Artísticas e Culturais, 2016.

ODIN, Roger; PÉQUIGNOT, Julien. De la sémiologie à la sémio-pragmatique, du texte aux espaces mentaux de communication. Entretien avec Roger Odin, réalisé par Julien Péquignot. Communiquer. Revue de communication sociale et publique, n. 20, p. 120140, 2017. https://doi.org/10.4000/communiquer.2296

PINES, Jim; WILLEMEN, Paul. Questions of third cinema. London: British Film Institute, 1989.

RIESCO, Beatriz Leal. Historia y ansiedades de la crítica de los cines africanos a través de la persona y la obra de Med Hondo. El Futuro Del Pasado: Revista Electrónica de Historia, n. 5, p. 163-187, 2014. https://doi.org/10.14516/fdp.2014.005.001.008

SANOGO, Aboubakar. In focus: studying African cinema and media today. Cinema Journal, v. 54, n. 2, p. 114-120, 2015. https://doi.org/10.1353/cj.2015.0000

SCHNELL, Breanne. Stop comparing Nollywood to Hollywood: reorienting western understanding of Nigerian cinema. Undergraduate Library Research Award scholarship competition (2017-2018), University of Oregon, 2017, 30 p. Disponível em: http://hdl. handle.net/1794/23215. Acesso em: 26 jul. 2018. 
STAM, Robert. Introdução à teoria do cinema. Campinas, SP: Papirus Editora, 2000.

TCHEUYAP, Alexie. African cinema(s): definitions, identity and theoretical considerations, Critical Interventions - Journal of African Art History and Visual Culture, v. 5, n. 1, p. 10-26, jan. 2011a. Disponível em: https://doi.org/10.1080/19301944.2011.10781397 . Acesso em: 26 jul. 2018.

TCHEUYAP, Alexie. Postnationalist African cinemas. Manchester, UK: Manchester University Press, 2011b.

THACKWAY, Melissa. Africa shoots back: alternative perspectives in sub-Saharan francophone African film. Indiana University Press, 2003. https://doi.org/10.1163/18729037 afco asc 3012

UKADIKE, Nwachukwu Frank. Black African Cinema. Berkeley, Los Angeles, London: University of California Press, 1994.

\section{Dados dos autores:}

\section{José Francisco Serafim - serafimjf@gmail.com}

Professor e pesquisador do Programa de Pós-Graduação em Comunicação e Cultura Contemporâneas da Universidade Federal da Bahia (PósCom-UFBA). PósDoutorado na Filmuniversität Babelsberg Konrad Wolf e Doutorado em Cinema Documentário (antropológico) pela Universidade Paris X - Nanterre (2000).

\section{Ana Camila Esteves - anacamila.ufba@gmail.com}

Doutoranda e Mestra em Comunicação e Cultura Contemporâneas pela Universidade Federal da Bahia (PósCom-UFBA).

\section{Morgana Gama de Lima - morganagama@gmail.com}

Doutoranda em Comunicação e Cultura Contemporâneas pela Universidade Federal da Bahia (PósCom-UFBA) e Mestra em Cultura e Sociedade pela UFBA.

\section{Endereço dos autores:}

Universidade Federal da Bahia, Secretaria do Programa de Pós-Graduação em Comunicação e Cultura Contemporâneas

Av. Barão de Geremoabo, s/n, Ondina, 40.170-115 - Salvador (BA) - Brasil 